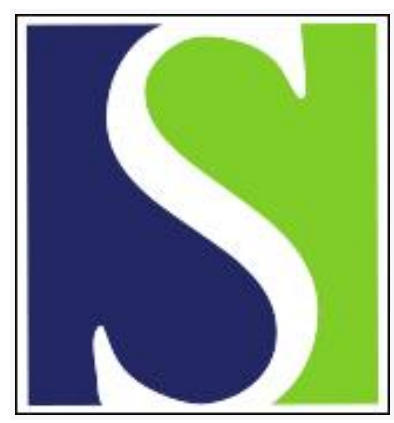

Scand J Work Environ Health 2009;35(1):1-5

https://doi.org/10.5271/sjweh.1304

Issue date: 00 Jan 2009

Work ability-a comprehensive concept for occupational health research and prevention

by Ilmarinen J

Affiliation: Finnish Institute of Occupational Health, Topeliuksenkatu 41 a A, Fl-02500, Finland. juhani.ilmarinen@ttl.fi

Refers to the following texts of the Journal: 2008;34(1):55-65

2007;33(5):351-357 2004;30(5):339-349 2003;29(2):143-151

2002;28(3):184-190 2008;34(2):81-82 2009;35(1):37-47 1997;23

suppl 1:49-57 1997;23 suppl 1:1-71

The following articles refer to this text: $2010 ; 36(1): 34-41$; 2010;36(5):404-412; 2010;36(6):515-516; 2011;37(6):455-463; 2011;37(6):451-453; 2012;38(6):600-603; 2013;39(5):456-467; 2014;40(3):244-251; 2014;40(4):428-431; 2014;40(5):473-482; 2015;41(1):36-42; 2015;41(1):24-35; 2015;41(4):338-346; 2016;42(4):273-279; 2016;42(6):490-499; 2017;43(1):34-41; 2017;43(2):146-154; 2017;43(5):465-474; 2018;44(1):37-46; 2018;44(2):134-146; 2018;44(1):58-68; 2020;46(2):168-176; $2022 ; 48(4): 312-321$

Key terms: editorial; occupational health; occupational health prevention; occupational health research; prevention; research; work ability

This article in PubMed: www.ncbi.nlm.nih.gov/pubmed/19277432

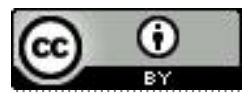




\section{Work ability—a comprehensive concept for occupational health research and prevention}

The use of the work ability index began in the early 1980s in Finland. The basic scientific question was how long workers and employees are able to work and to what extent being able to work depends on the work content and job demands. In those days, job-dependent retirement ages from 53 years (deep sea divers) to 63 years (administrative jobs) were common in Finnish municipal occupations. The early-retirement options were rather broad, and the costs of work disability tended to increase. The public discussion was dominated by a fear of an increasing trend towards work disability and a shortening of work careers due to a variety of reasons, not only medical in nature. A social need for a new, positive approach was obvious, as represented by work ability. Using the stress-strain concept, a multidisciplinary study group developed and validated the work ability index and started studies among municipal employees ( $N=6257$ ) over 45 years of age and repeated them in 1985, 1991, and $1997(1,2)$. One of the main findings was that the mean work ability index declined significantly among $30 \%$ of the participants, remained rather unchanged among 60\%, and improved among 10\% over an 11-year period for both genders, as well as for physically, mentally, or mixed (physical and mental) demanding jobs. A logistic regression model indicated that factors related to management, ergonomics, and lifestyle explained both the decline and improvement in work ability during aging $(3,4)$. The consequences of the findings were significant and long lasting. First, the Finnish social partners agreed in 1989 about the maintenance and promotion of work ability in workplaces. Second, the promotion concept of work ability was created and validated in private, municipal, and government branches (5).Third, occupational health professionals, physicians, and nurses, were trained by the Finnish Institute of Occupational Health in the use of the work ability index. After 1993, translations of the questionnaire for the work ability index were used by Austrian and Dutch research groups, and, today, this questionnaire is available in 26 languages. The use of the index has become common in research worldwide. The Ageing and Work Committee of the International Commission on Occupational Health $(\mathrm{ICOH})$ and the Aging Committee of the International Ergonomics Association (IEA) served as important platforms for further implementation of the work ability index internationally. The number of publications of scientific conferences and symposia dealing with the work ability index is considerable (6-14).

In this issue of the Scandinavian Journal of Work, Environment \& Health, a new approach to the study of work ability has been introduced by Feldt and her colleagues (15). They used a person-oriented approach in studying the development trajectories of managers' work ability over a 10-year period. They identified the following five trajectories for Finnish managers $(\mathrm{N}=1033)$ over the follow-up period: (i) work ability consistently excellent, (ii) work ability good but slowly declining, (iii) work ability declined from good to poor, (iv) work ability improved from moderate to good, and (v) work ability consistently poor. The mean retirement age was the highest (61.3 years) in the most favorable work ability groups and the lowest (55.4 years) in the group "work ability consistently poor". Young age, higher management position, high job control, supportive organizational climate, and high organizational commitment at baseline were significant predictors for a positive development of work ability. Feldt et al concluded that aging and lower-level managers are at risk of an unfavorable development with respect to their work ability. More attention should be given to their psychosocial work conditions in organizations in order to prevent poor work ability. 
These results are in accordance with earlier findings of variable-oriented analyses. However, the latent groups, which differed in their size and the development course (as determined by the work ability index), detected different trajectories among a sample of managers. Managerial position as such did not prevent the work ability index from declining. Managers' work ability index depends also on the quality of their worklife. Another interesting finding was the linear and significant decline of the work ability index in one group and the linear improvement in another group of managers over the 10-year period. The linearity of the change suggests a "tracking" effect. Once a manager has entered adverse conditions, it is difficult to leave and vice versa - a supporting environment helps managers to remain in favorable conditions over a period of 10 years. However, more data points would be necessary to verify the linearity of the change in the work ability index. In addition, it would be interesting to study the tracking effect for other occupational groups using the person-oriented approach.

In the study by Feldt et al (16), the level of work ability was related to the age of retirement-the better the work ability index the later the retirement-a difference of about 6 years. A similar finding was observed earlier among municipal employees. In that study, an excellent or good work ability index before retirement was significantly related to a better work ability index, physical work capacity, health, and life quality 5 years after retirement when the comparison group was comprised of those having a poor work ability index before retirement. These findings are important in that they indicate that the quality of a person's active period after retirement (known as the "third age") probably depends on the quality of worklife. Therefore, the investments in the third age should be made during a person's worklife. Retirement as such does not necessarily guarantee a good, limitation-free, and independent life. The value of a good worklife will be realized during the rest of one's life. Therefore, preventing harmful effects and increasing the positive features of worklife are important. However, more research is needed to evaluate the positive and negative factors of worklife in explaining the quality of the third age. From the research point of view, better collaboration between occupational health research and gerontology should be developed. In the ICOH Aging and Work Committee, a concept of occupational gerontology has been introduced by Professor Willem Goedhard, chairman of the Committee in 1989-2005. Because we are living longer and we should be working longer than ever before, a social order for occupational gerontology is available.

The concepts of work ability have changed and developed during the last decade in a more holistic and versatile direction. The health-based definition of work ability has been paired with integrated models in which work ability is created and promoted by many factors. The definition of work ability depends on whether it is considered from the point of view of occupational health, social insurance, or, for example, rehabilitation. In occupational health, the work ability concept is built on the balance between a person's resources and work demands. A person's resources consist of health and functional abilities, education and competence, and values and attitudes. Work, on the other hand, covers the work environment and community, as well as the actual contents, demands, and organization of work. Management with all its dimensions belongs to the features of work $(17,18)$.

Work ability is primarily a question of a balance between work and personal resources. In practice, people search for an optimal balance throughout their entire worklife. This optimal balance may be very different in different phases of worklife. In order to find a balance, work and personal resources need to be continuously combined. Personal resources change, for example, with age, whereas work demands change, for example, with globalization and new technology. The factors affecting work ability are therefore continuously changing.

The maintenance and promotion of work ability requires good cooperation between supervisors and employees. However, neither can ensure that work ability will not change; instead the responsibility is shared between the employer and the employee. Work ability is not, however, only a matter of these two. The management and human resource policy of the enterprise sets the framework for the promotion of work ability, and the work community can also play an important role in supporting the work ability 
of its members. Central roles are also played by the occupational health care and occupational safety organization. The tasks fixed by law for occupational health care in Finland include the maintenance of employees' work ability. Workforce aging and work ability are demanding challenges for occupational health professionals (19). The occupational safety organization, in turn, uses its competence to prevent and fend off the work risks that threaten work ability.

Work ability is not separated from life outside work. Family and a person's close community (relatives, friends, acquaintances) can also affect a person's work ability in many different ways throughout life. Making work and family life compatible has become more important. Society and the operational environment create the infrastructure, services, and rules according to which enterprises and employees' work ability can be supported. The importance of the different dimensions of work ability has been studied using the representative Finnish material of the Health 2000 project. The results of the cross-sectional data show that, among people of all ages, health, functional capacity, and the characteristics of one's work are the most statistically significant factors behind work ability (20).

Together, aging and the work ability index have formed one of the most interesting, but demanding, research targets. Unfortunately, only a limited number of follow-up or longitudinal studies is available. A common finding has been the decline of the work ability index during aging. It evokes several questions. What is the role of aging per se? Or, is it more work-related factors that define the work ability index? The latter opinion is supported by the complexity of the dimensions of work ability. Health is age-related, and therefore it is obvious that the work ability index, containing several health items, shows a declining trend with age. However, good health does not guarantee a good work ability index, and health problems do not mean that the work ability index is irreversibly lost (20). Different diseases play different roles in work ability (21). Using the first item of the work ability index, "work ability related to lifetime best" (scale 0-10 points), which is an "age-free" item, shows also a rather linear decline with age that suggests that there may be an aging effect as such. In physical (like installation) and mixed (like transport) work, the work ability index was shown to decline faster than in mentally demanding (like administration) work among men aged 51-58 years. Respectively, among women in physical work, the decline of the work ability index was faster than in mixed (nursing) or mental work (teaching) (3). These findings suggest that the effect of aging is also job dependent. On the other hand, the result can be also an indication of the overestimation of the work ability index at younger ages. The subjective evaluation of the work ability index after short experiences in worklife may be more unrealistic in nature than the evaluation among older groups. The results of young adults show that there is already a great variation in the work ability index according to the employment status of 18- to 29-year-old persons. The work ability index of the unemployed and of those who are at home was found to be poorer than that of others. What is the cause and effect remains unclear. A low level of education and unemployment has been found to be the greatest risks to the work ability of the young. On the other hand, the work ability index of employed young adults seems to be related to their quality of life, appreciation at work, and physical fitness (22). The predictors of the work ability index can be generation-related, which emphasizes the need for more in-depth research for young, middle-aged, and older persons. The young generation needs special attention to ensure their work ability because they are both the minority of the workforce and, as newcomers, they face the high expectations of their employers. Fixed-term employment is probably not the best background for their work ability (23).

In spite of the active international research on work ability during the last decade, many new research challenges can exist (24). For example, some specific research questions can be formulated according to the recent understanding over the dimensions of work ability as follows: (i) health and functional capacities: why are not all healthy people able to work, and not all sick people have problems with their work ability; (ii) education and competence: why is a high level of education strongly related to good work ability, but perceived work expertise is not; (iii) values and attitudes: can work enjoyment, work enthusiasm, 
and commitment compensate for health-related problems with work ability; (iv) work and leadership: do the work characteristics that support the work ability of men and women differ, how is the functioning of the work community reflected in the work ability of the individual worker, what is the role of flexible worktime arrangements with respect to work ability, how does a constant change in worklife affect work ability, and what is the role of fixed-term work with respect to work ability; and (v) worklife balance: what is the role of family and a person's close community with respect to work ability?

In addition, a better understanding of the following research topics are needed: (i) what is the relationship between productivity and work ability, (ii) what interventions to promote work ability are cost effective, (iii) what is the work ability of the unemployed, immigrants, and retired persons, (iv) what is the role of culture in work ability, and (v) what is the role of work ability in the third age and life expectancy? It is obvious that more longitudinal studies on work ability are necessary. In addition, there have been only a few well-designed interventions covering several dimensions of work ability. Methodological research activities are also welcome. Because the work ability index itself cannot explain the changes that occur during aging, standardized methods to identify the important determinants of work ability are needed.

The increasing number of different language translations of the work ability index and its global use provides good possibilities for international networks and databanks related to the work ability index. National networks and databanks dealing with the work ability index are currently under construction in Finland, Germany, and the Netherlands. Asian (Japan, South Korea, and Taiwan), Australian, and South American (Brazil) data banks are under discussion. The databanks will provide both new possibilities for research and strengthen the networks dealing with the work ability index worldwide.

The Scandinavian Journal of Work, Environment \& Health has shown a good understanding of the work ability concept much earlier than many other scientific journals and has provided a fruitful platform for work ability research since 1991. Since the basic supplements presenting longitudinal studies in the 1990s (1,2), interesting articles providing new information on work ability with respect to the following themes has been published by the Scandinavian Journal of Work, Environment \& Health: physical and psychological prerequisites in relation to work ability among office workers (25), work conditions and socioeconomic inequalities in work ability (26), worklife expectancies and the state of work ability (27), work-related factors and individual characteristics of work ability among Dutch construction workers (28), physical-activity programs to reduce musculoskeletal symptoms among office workers (29), and worksite interventions involving physical exercise and reduced workhours (30). My devoted wish is that new, high-quality articles on work ability will appear frequently in this journal also in the future.

The complexity of work ability is a great challenge both for research and prevention in occupational health. Evidence-based concepts to prevent work ability from declining and to promote it in the demanding context of globalization, new technology, and demographic change are urgently needed. The most important asset of employees in worklife is their work ability. Because enterprise profits are made possible by the work ability of its personnel, the enterprise has a central role in supporting and promoting the work ability of its employees.

\section{References}

1. Ilmarinen J, editor. The aging worker. Scand J Work Environ Health 1991;17 suppl 1.

2. Tuomi K, editor. Eleven-year follow-up of aging workers. Scand J Work Environ Health. 1997;23 suppl 1.

3. Ilmarinen J, Tuomi K, Klockars M. Changes in the work ability of active employees over an 11-year period. Scand J Work Environ Health. 1997;23 suppl 1:49-57.

4. Ilmarinen J, Tuomi K. Past, present and future of work ability. In: Ilmarinen J, Lehtinen S. Past, present and future of work ability. Helsinki: Finnish Institute of Occupational Health; 2004. People and Work, Research Reports 65, p 1-25.

5. Ilmarinen J, Louhevaara V, editors. FinnAge—respect for the aging: action programme to promote health, work ability and well-being of ageing workers in 1990-96. Helsinki; Finnish Institute of Occupational Health; 1999. People and Work, Research reports 26 .

6. Ilmarinen J, editor. Aging and work. In: International scientific symposium on aging and work, 28-30 May 1992; Haikko, 
Finland: Respect for the ageing_programme. Helsinki: Finnish Institute of Occupational Health; 1993. Proceedings 4.

7. Goedhard WJA, editor. Aging and work. The Hague: Pasmans; 1992.

8. Goedhard WJA, editor. Aging and work 3. The Hague: Pasmans; 1996.

9. Kilbom Å, Westerholm P, Hallsten L, editors. Work after 45?: proceedings from a scientific conference held in Stockholm 22-25 September 1996. Solna: National Institute for Working life; 1997. Arbete och Hälsa 29.

10. Winn FJ, Nielsen J, Fallentin N, Simonsen L, editors. Second international conference on aging and work [special issue]. Exp Aging Res. 1999;25(4).

11. Kumashiro M, editor. Aging and work. London, New York: Taylor and Francis; 2003.

12. Ilmarinen J, Lehtinen S, editors. Past, present and future of work ability: proceedings of the 1st International Symposium on Work Ability, 5-6 September 2001, Tampere, Finland. Helsinki: Finnish Institute of Occupational Health; 2004. People and Work, Research Reports 65.

13. Costa G, Goedhard WJA, Ilmarinen J, editors. Assessment and promotion of work ability, health and well-being of ageing workers. Amsterdam: Elsevier; 2005. International Congress Series 1280.

14. Kumashiro M, editor. Promotion of work ability towards productive aging: selected papers of the 3rd International Symposium on Work Ability, Hanoi Vietnam, 22-24 October 2007. London: CRC Press/Balkema, Taylor and Francis Group; 2009.

15. Feldt T, Hyvönen K, Mäkikangas A, Kinnunen U, Kokko K. Development trajectories of Finnish manager's work ability over a 10-year period. Scand J Work Environ Health. 2009;35(1):37-47.

16. Tuomi K, Huuhtanen P, Nykyri E, Ilmarinen J. Promotion of work ability, the quality of work and retirement. Philadelphia (PA); Hanley \& Belfus, Inc; 2001. Occupational Medicine: state of the art reviews, volume 5, p 5, 318-24.

17. Ilmarinen J. Towards a longer worklife!: ageing and the quality of worklife in the European Union. Helsinki: Finnish Institute of Occupational Health, Ministry of Social affairs and Health; 2006.

18. Ilmarinen J, Gould R, Järvikoski A, Järvisalo J. Diversity of work ability. In: Gould R, Ilmarinen J, Järvisalo J, Koskinen S, editors. Dimension of work ability: results of the Health 2000 Survey. Helsinki: Finnish Centre of Pensions, The Social Insurance Institution, National Public Health Institute, Finnish Institute of Occupational Health; 2008.

19. Ilmarinen J. The ageing workforce—challenges for occupational health [editorial]. Occup Med. 2006;56:361-4

20. Gould R, Ilmarinen J, Järvisalo J, Koskinen S, editors. Dimension of work ability: results of the Health 2000 Survey. Helsinki; Finnish Centre of Pensions, The Social Insurance Institution, National Public Health Institute, Finnish Institute of Occupational Health; 2008.

21. Koskinen S, Martelin T, Sainio P, Gould R. Factors affecting work ability. In: Gould R, Ilmarinen J, Järvisalo S, Koskinen S, editors. Dimension of work ability: results of the Health 2000 Survey. Helsinki: Finnish Centre of Pensions, The Social Insurance Institution, National Public Health Institute, Finnish Institute of Occupational Health; 2008. p 65-79.

22. Seitsamo J, Tuomi K, Ilmarinen J. Work ability of young workers. In: Gould R, Ilmarinen J, Järvisalo J, Koskinen S, editors. Dimension of work ability: results of the Health 2000 Survey. Helsinki: Finnish Centre of Pensions, The Social Insurance Institution, National Public Health Institute, Finnish Institute of Occupational Health; 2008. p 131-7.

23. Burdorf A. The importance of solid employment for health [editorial]. Scand J Work Environ Health. 2008;34(2): 81-2.

24. Gould R, Ilmarinen J, Järvisalo J, Koskinen S. Dimension of work ability—summary and conclusion. In: Gould R, Ilmarinen J, Järvisalo S, Koskinen S, editors. Dimension of work ability: results of the Health 2000 Survey. Helsinki: Finnish Centre of Pensions, The Social Insurance Institution, National Public Health Institute, Finnish Institute of Occupational Health; 2008. p 165-75.

25. Sjögren-Rönkä T, Ojanen MT, Leskinen EK, Mustalampi ST, Mälkiä EA. Physical and psychological prerequisites of functioning in relation to work ability and general subjective well-being among office workers. Scand J Work Environ Health. 2002;28(3):184-90.

26. Aittomäki A, Lahelma E, Roos E. Work conditions and socioeconomic inequalities in work ability. Scand J Work Environ Health. 2003;29(2):159-65.

27. Nurminen M. Working population health metrics [review]. Scand J Work Environ Health 2004;30(5):339-49.

28. Alavinia SM, van Duivenbooden C, Burdorf A. Influence of work-related factors and individual characteristics on work ability among Dutch construction workers. Scand J Work Environ Health 2007;33(5):351-7.

29. Blangsted AK, Søgaard K, Hansen EA, Hannerz H, Sjøgaard G. One-year randomized controlled trial with different physical-activity programs to reduce musculoskeletal symptoms in the neck and shoulders among office workers. Scand J Work Environ Health. 2008;34(1):55-65.

30. von Thiele Schwarz U, Lindfors P, Lundberg U. Health-related effects of worksite interventions involving physical exercise and reduced workhours. Scand J Work Environ Health. 2008;34(3):179-88.

\section{Juhani IImarinen}

Professor Emeritus, Finnish Institute of Occupational Health

Visiting Professor of Occupational Wellbeing and Work Ability,

Swinburne University of Technology, Melbourne, Australia

[E-mail: juhani.ilmarinen@ttl.fi

jilmarinen@swin.edu.au

juhani.ilmarinen@jic.fi] 